\title{
MUDANÇAS NA METODOLOGIA TRADICIONAL DE MATEMÁTICA: UMA NECESSIDADE PARA A INCLUSÃO
}

\section{ARTIGO ORIGINAL}

SOARES, Aline Maria de Almeida ${ }^{1}$

SOARES, Aline Maria de Almeida. Mudanças na metodologia tradicional de matemática: uma necessidade para a inclusão. Revista Científica Multidisciplinar Núcleo do Conhecimento. Ano. 06, Ed. 08, Vol. 04, pp. 131-143. Agosto 2021. ISSN: 2448-0959, Link de acesso:

https://www.nucleodoconhecimento.com.br/educacao/mudancas-na-metodologia, DOI: 10.32749/nucleodoconhecimento.com.br/educacao/mudancas-na-metodologia

\section{RESUMO}

Este artigo aborda como tema central as modificações necessárias na metodologia tradicional de matemática, sendo estas uma necessidade para a inclusão dos alunos nas escolas, pois o método utilizado mediante quadro, lápis e livro didático não são suficientes para garantir a inclusão de todos os alunos em uma sala de aula. Sabese que a educação é a ferramenta que permite moldar a realidade, a qual deve estar voltada para a formação da sociedade, sendo essencial para a evolução do ser humano. Nesse artigo será apresentado uma pesquisa bibliográfica de caráter qualitativo, tendo como objetivo apresentar métodos que podem auxiliar os docentes na transmissão do ensino de matemática, por meio de adaptações de materiais manipulativos, os quais devem servir para auxiliar na transmissão do conhecimento, e na aprendizagem de todos os estudantes, ajudando assim na inclusão dos alunos com necessidades educacionais especiais em uma sala de aula regular. Observa-se que a educação inclusiva, busca incluir os alunos com deficiências nas turmas

\footnotetext{
${ }^{1}$ Mestranda em Educação, pelo Institute Theology Science Florida, Orlando- USA.FL; Pós graduada em Ensino de Matemática, pela AESA/CESA. PE Arcoverde-PE, Brasil; Graduada em Matemática pela AESA/CESA Arcoverde-PE, Brasil.

RC: 94435

Disponível em: https://www.nucleodoconhecimento.com.br/educacao/mudancas-na$\underline{\text { metodologia }}$
} 
regulares do ensino. Percebe-se que no contexto da educação, as vezes o estudante sente muita dificuldade, principalmente nas operações matemáticas. Desta forma o problema de pesquisa foi investigar a seguinte questão: $O$ que o docente pode utilizar para mudar a maneira tradicional de transmitir os conteúdos de matemática, a fim de promover a inclusão dos alunos com necessidades especiais na educação escolar regular, de modo que o aluno possa desenvolver habilidades e entender melhor os novos conhecimentos adquiridos, facilitando o ensino/aprendizagem? Buscou-se o que autores dizem sobre o tema em produções acadêmicas publicadas em livros, revistas eletrônicas, artigos, dissertações e monografias. Sendo assim, conclui-se que os métodos apresentados durante a pesquisa contribui para o desenvolvimento da aprendizagem, e para a inclusão dos alunos na sala de aula, pois na medida que é oferecido ao estudante maneiras diferentes de aprender o conteúdo, ele se sente curioso para observar como realizar a atividade com o aquele material, e o educador consegue chamar a atenção dos alunos, de modo que os estudantes conseguem desenvolver suas habilidades com os materiais manipulativos, facilitando assim o processo de aprendizagem.

Palavras-chave: Educação, Matemática, Adaptação, Inclusão.

\section{INTRODUÇÃO}

A educação é a ferramenta que permite moldar a realidade, a qual deve ser voltada para a formação da sociedade, sendo essencial para a evolução do ser humano. Desta forma a Educação de um modo geral, permite a transferência de costumes, valores e hábitos, os quais são transferidos de geração em geração. No contexto da educação, encontra-se a Educação escolar, a qual está voltada para a formação dos cidadãos, qualificando-os para o mercado de trabalho, para o exercício da cidadania e para as várias práticas sociais. Junto com a educação escolar, encontra-se a educação inclusiva, a qual busca incluir os alunos com deficiências nas turmas regulares do ensino. Percebe-se que há uma grande mobilização para que todas as pessoas sejam incluídas na sociedade, e na escola não poderia ser diferente, a 
mesma deve acolher todos os alunos independentemente de algum tipo de necessidade especial.

Segundo Werneck (1997),

A palavra inclusão remete-nos a uma definição mais ampla, indicando uma inserção total e incondicional, esta exige a transformação da escola, pois defende a inserção no ensino regular de alunos com quaisquer déficits e necessidades, cabendo às escolas se adaptarem às necessidades dos alunos, ou seja, a inclusão acaba por exigir uma ruptura com o modelo tradicional de ensino.(WERNECK, 1997, p. 82).

Pontes et al. (2010) corrobora e afirma que, os alunos com deficiência devem ser incluídos nas escolas comuns, inseridos nas turmas com os demais alunos, porque se for seguir a política de escolas voltadas somente para os alunos com deficiência, isso seria um retrocesso histórico.

Observa-se que de acordo com a alteração no inciso III com a redação dada pela lei de número 12.796 de 2013, é estabelecido quais são as garantias que os estudantes terão para uma educação mais inclusa. Sendo assim,

Art. 4ํ O dever do Estado com educação escolar pública será efetivado mediante a garantia de: I - educação básica obrigatória e gratuita dos 4 (quatro) aos 17 (dezessete) anos de idade, organizada da seguinte forma a) pré-escola; b) ensino fundamental; c) ensino médio; [...]

III - atendimento educacional especializado gratuito aos educandos com deficiência, transtornos globais do desenvolvimento e altas habilidades ou superdotação, transversal a todos os níveis, etapas e modalidades, preferencialmente na rede regular de ensino. (BRASIL, 2013, p.1).

Sabe-se que a educação escolar começar nos primeiros anos de vida, a qual é ofertada em três níveis, Educação infantil que vai de 0 a 5 anos, Ensino Fundamental que vai de 6 a 14 anos e o Ensino Médio que é de 15 a 17 anos.

A primeira etapa da formação escolar do ser humano é a creche, a qual deve atender crianças de 0 a 3 anos e depois a pré - escola que atende crianças na faixa etária de 4 a 5 anos, esses dois primeiros momentos da educação básica, são 
primordiais, pois é iniciado a alfabetização, sendo este um processo que é demorado mais essencial para a aprendizagem, onde 0 aluno adquire a coordenação motora, de modo que a criança aprende a segurar um lápis, borracha, depois desse processo o aluno consegue cobrir as palavras feitas pelos docentes, entre outras atividades.

Destaca - se nesta fase o papel do educador, pois ele tem a missão de criar estratégias fundamentais, para que as crianças aprendam da melhor maneira possível. Nesta fase, percebe-se que muitas vezes são criadas diferentes maneiras do aluno desenvolver sua capacidade intelectual. No entanto as vezes o estudante sente muita dificuldade, principalmente nas operações matemáticas, por exemplo, precisando assim de um reforço escolar de matemática, visto que muitas pessoas a consideram como uma disciplina difícil, a qual gera muitas reprovações.

Percebe-se que no contexto da educação, os pais muitas vezes não querem colocar e nem permitem que os filhos frequentem uma aula de reforço, por achar que não vai surtir efeito para a aprendizagem dos mesmos. Acredita-se que todos os alunos com dificuldades devem ter um reforço para melhorar a compreensão. Quando se fala todos os alunos, incluem-se os alunos com deficiência também, pois os mesmos também precisam de uma atenção especial de acordo com a sua necessidade, para poder acompanhar o nível da turma e dos seus colegas, para que dessa forma o aluno esteja realmente incluso na aprendizagem.

Sendo assim, o problema de pesquisa foi investigar a seguinte questão: $O$ que o docente pode utilizar para mudar a maneira tradicional de transmitir os conteúdos de matemática, afim de promover a inclusão dos alunos com necessidades especiais na educação escolar regular, de modo que o aluno possa desenvolver habilidades e entender melhor os novos conhecimentos adquiridos, facilitando 0 ensino/aprendizagem?

Desta forma o objetivo geral é apresentar métodos que podem auxiliar os docentes na transmissão do ensino de matemática, por meio de adaptações de materiais RC: 94435

Disponível em: https://www.nucleodoconhecimento.com.br/educacao/mudancas-nametodologia 
manipulativos, os quais devem servir para auxiliar na transmissão do conhecimento, e na aprendizagem de todos os estudantes, ajudando assim na inclusão dos alunos com necessidades educacionais especiais em uma sala de aula regular.

A metodologia deste artigo será por meio de uma pesquisa bibliográfica de caráter qualitativo, o qual permitirá analisar o que os autores dizem sobre o tema em produções acadêmicas publicadas em livros, revistas eletrônicas, artigos, dissertações e monografias.

\section{DESENVOLVIMENTO}

\subsection{A EDUCAÇÃO INCLUSIVA}

Percebe-se que a maneira como as aulas de matemática é ministrada, exploradas mediante quadro e livro didático, tendem a serem menos estimulantes, podendo dificultar o interesse e a inclusão de todos os alunos.

Desta forma, os professores sentem muita dificuldade para realizar a inclusão dos alunos com necessidades especiais nas aulas. Outro fator que contribui de forma negativa para a inclusão dos alunos é a falta de capacitações para os docentes, pois os mesmos não recebem formações voltadas para atender os alunos com deficiência, pois existem vários tipos de deficiências, tais como, deficiência visual; deficiência motora; deficiência mental; deficiência auditiva entre outras.

No entanto, observa-se que mesmo o professor não recebendo formação adequada, para atender a cada particularidade dos alunos, é imposto por a escola que o mesmo faça atividades diferenciadas para os estudantes. Desta forma, percebe-se que a inclusão dos alunos nas salas de aula regular é um pouco difícil, tanto para os alunos como para os professores, pois as vezes o professor não consegue dar uma atenção exclusiva a estes alunos, sendo necessário um professor de apoio para estes alunos, pois o professor regente da turma não consegue atender a todos. 
Sendo assim, a escola deve proporcionar aos estudantes um atendimento educacional especializado, de modo que seja garantido aos alunos com deficiência, materiais adequados para todas as necessidades dos estudantes, os quais devem facilitar a inclusão dos alunos na sala de aula regular. Outro fator importante, que deve ser levado em conta é a capacitação dos professores, para que os mesmos consigam proporcionar atividades diferenciadas para atender as particularidades de cada aluno (FACHIN, 2018).

Uma maneira interessante de ajudar os alunos que sentem dificuldades, para acompanhar os conteúdos, é através da aula de reforço, a qual pode ser ofertada pôr a escola. Entretanto para que essa aula traga frutos, é preciso que os pais tenham a consciência de que os filhos com deficiência precisam de aulas de reforço, da mesma forma que os alunos que não possuem nenhuma deficiência precisam, para que dessa forma eles entendam melhor o conteúdo, e na sala de aula possam se sentir realmente incluídos, gerando assim uma melhor aprendizagem. Deve-se deixar claro que os alunos com deficiência, precisam de reforço com um professor especializado na sua deficiência e na disciplina estudada.

Sabe-se que, a educação inclusiva é garantida por a declaração da Salamanca (1994), ela traz vários princípios fundamentais, os quais ressaltam que,

Toda criança tem direito fundamental à educação, e deve ser dada a oportunidade de atingir e manter o nível adequado de aprendizagem; toda criança possui características, interesses, habilidades e necessidades de aprendizagem que são únicas; sistemas educacionais deveriam ser designados e programas educacionais deveriam ser implementados no sentido de se levar em conta a vasta diversidade de tais características e necessidades; aqueles com necessidades educacionais especiais devem ter acesso à escola regular, que deveria acomodá-los dentro de uma Pedagogia centrada na criança, capaz de satisfazer a tais necessidades; escolas regulares que possuam tal orientação inclusiva constituem os meios mais eficazes de combater atitudes discriminatórias criando-se comunidades acolhedoras, construindo uma sociedade inclusiva e alcançando educação para todos; além disso, tais escolas provêm uma educação efetiva à maioria das crianças e aprimoram a eficiência e, em última instância, o custo da eficácia de todo o sistema educacional (DECLARAÇÃO DE SALAMANCA, 1994, p. 1).

RC: 94435

Disponível em: https://www.nucleodoconhecimento.com.br/educacao/mudancas-nametodologia 
Além disso, é necessário ressaltar que, tanto a aula como o reforço, deve ser regido da melhor maneira possível, de modo que nenhum aluno se sinta inferior ao outro, que se sinta incluído, pois é necessário que os alunos percebam que existem pessoas diferentes, as quais precisam do direito de ser tratados iguais, mesmo quando as diferenças os inferioriza, pois existem diferenças e igualdades, na sociedade. (MANTOAN,2004)

Kupfer (2001) corrobora e afirma que,

A inclusão precisa ser feita de modo a preservar um princípio ético do qual andamos meio esquecidos - 0 direito de todos à vida - e produz ainda, efeitos terapêuticos para a criança cuja subjetivação encontra obstáculos que um velho pátio de escola ainda pode ajudar a transpor. (KUPFER, 2001, p. 80)

De modo que, as diversidades existem e não devem ser vistas como obstáculos, ou impedimentos, porque a educação inclusiva significa ensinar a todos os indivíduos em um mesmo nível escolar, sem fazer nenhuma diferença, pois as oportunidades devem ser as mesmas para todos, ampliando assim a visão de um mundo, capaz de incluir a todos sem nenhum preconceito, pois

Não se pode afirmar que não existem conhecimentos especiais para os cegos, para os surdos e os mentalmente atrasados. Porém esses conhecimentos e essas aprendizagens especiais há que se subordiná-los à educação comum, à aprendizagem comum, a pedagogia especial deve estar diluída na atividade geral da criança. (VIGOTSKY, 1997, p. 65).

Sendo assim, para que todas as crianças tenham as mesmas oportunidades é preciso que elas aprendam com o mesmo nível, não sendo assim necessário que o professor faça atividades com o nível mais baixo. No entanto é necessário que haja,

[...] uma reestruturação do sistema educacional, ou seja, uma mudança estrutural no ensino regular, cujo objetivo é fazer com que a escola se torne inclusiva, um espaço democrático e competente para trabalhar com todos os educandos, sem distinção de raça, classe, gênero ou características pessoais, baseando-se no princípio de que a diversidade deve não só ser aceita como desejada. (BRASIL, 2001, p. 40). 
Observa-se, que da mesma forma que a diversidade deve ser desejada e aceita por a sociedade, pôr os alunos, a disciplina de matemática também deve ser aceita por os estudantes, e a maneira tradicional de ensiná-la também deve sofrer mudanças, de modo que o docente apresente ao aluno uma maneira mais lúdica para contextualizar o conteúdo, utilizando materiais manipulativos nas aulas. Outra mudança que deve ser tomada é a forma como o professor de reforço de matemática utiliza para ensinar, pois o mesmo também deve utilizar materiais específicos para os conteúdos, atendendo também as diferenças dos alunos.

\subsection{O LÚDICO NO ENSINO DE MATEMÁTICA PARA A INCLUSÃO}

Observa-se que o docente ao utilizar o lúdico no ensino de matemática na sala de aula, e nas aulas reforço, ele está transformando os assuntos em algo prazeroso, tanto para os alunos com deficiência (dando ênfase aos alunos com deficiência visual), pois os mesmos vão ter a oportunidade de manusear o objeto, e não ficar imaginando o que o professor está querendo explicar, já os alunos sem nenhuma deficiência vão entender melhor o assunto.

Até porque, com a utilização do lúdico o aluno pode desenvolver habilidades, e adquirir valores esquecidos, sendo uma ferramenta pedagógica capaz de ajudar o aluno a se socializar, a entender melhor os novos conhecimentos adquiridos durante a atividade, utilizando também a sua criatividade, de modo que possam desenvolver a cultura, valorizando assim as relações (DOS SANTOS, 2010, p. 16).

Silva Santos (2015) corrobora e afirma que, o professor deve entender que ao utilizar o lúdico a criança aprende brincando, adquirindo habilidades ao experimentar a nova brincadeira com o material proposto por o educador, de modo que as atividades proporcionem aos estudantes o desenvolvimento do pensamento, da linguagem, desenvolvendo assim uma melhor concentração, que o ajudará a aumentar a autoconfiança e a autonomia, gerando assim um bom desempenho dos alunos na escola. 
Percebe-se que os alunos devem ser incluídos nas aulas de matemática de uma maneira divertida, diferente da tradicional, pois ao abordar os assuntos é preciso que todos os alunos se sintam acolhidos, e para que isso aconteça existem alguns jogos que podem ser confeccionados tanto pelo professor da turma, como pelo professor de reforço. Por exemplo, se na sala de aula existe alunos deficientes auditivos e deficientes visuais, é necessário que eles se sintam incluídos na aula, de modo que as suas limitações não os façam se sentir excluídos da turma. Desta forma ao ensinar contagem dos números, por exemplo, pode-se utilizar um dominó, sendo este adaptado para cada especificidade. Sendo assim, o professor pode confeccionar um dominó em libras, um dominó em braile, e um dominó normal (Figura 1), de forma que o aluno perceba que está realizando a mesma atividade da turma.

Figura 1. Jogo de Dominó.

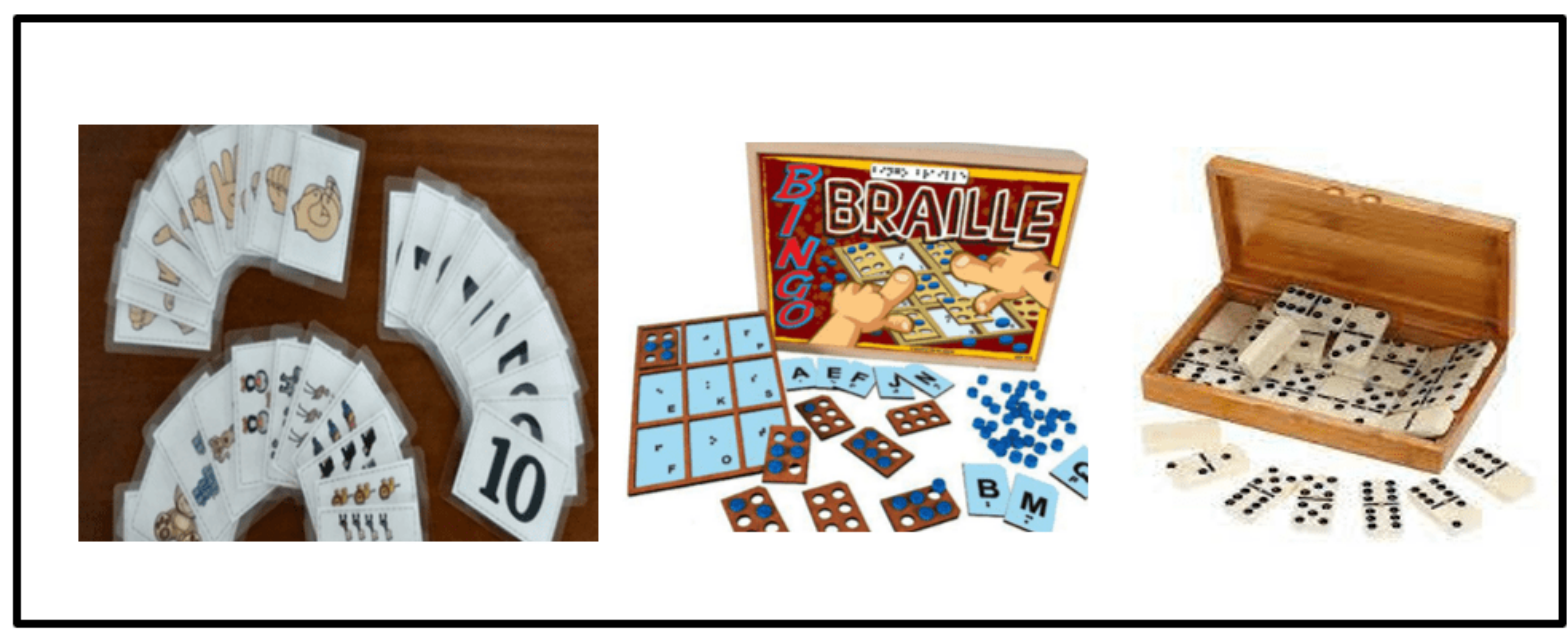

Fonte: $A$ autora (2021).

Com dominó é possível estudar vários assuntos, tais como: Soma, Subtração, ângulos, equação, basta somente adaptá-lo a cada aluno. Existem outros recursos, que podem ser utilizados por o professor tanto na sala de aula regular como na aula de reforço, tais como o Tangram, sendo este utilizado para trabalhar geometria plana, área, perímetro, entre outros assuntos, pois o mesmo é formado por sete 
peças geométricas; o Geoplano, sendo este utilizado para estudar área, formar figuras geométricas planas, e também usado para estudar o plano cartesiano; outro material interessante ressaltado por Azevedo (2006) é o Soroban, o qual é compreendido como um ábaco japonês, ele ajuda o aluno na contextualização do sistema de numeração, facilitando assim o entendimento, de maneira que os estudantes compreendem as posições das ordens e classes, pois cada haste vertical representa - uma ordem: unidade, dezena, centena; cada três hastes verticais representa- uma classe: simples, milhar, milhão, e assim por diante ; o Material dourado, o qual é muito utilizado para demonstrar o conceitos básicos da matemática; A máquina de Braile esta é muito importante para os alunos com deficiência visual, pois através dela os alunos podem escrever as anotações da aula, tendo assim a mesma oportunidade de aprendizagem que os alunos da sala possuem.

Outro material interessante para trabalhar na disciplina de matemática é o multiplano (Figura 2), desenvolvido para auxiliar o professor na aprendizagem de matemática e estatística, sendo uma ferramenta muito importante, pois proporciona a sociedade uma oportunidade de aprendizagem igual para todos os estudantes, sem preconceitos, possibilitando uma educação regular, inclusiva de forma que todos os alunos podem manuseá-lo.

RC: 94435

Disponível em: https://www.nucleodoconhecimento.com.br/educacao/mudancas-na$\underline{\text { metodologia }}$ 
Figura 2. Multiplano abordando os conteúdos de Álgebra, Geometria e Estatística.

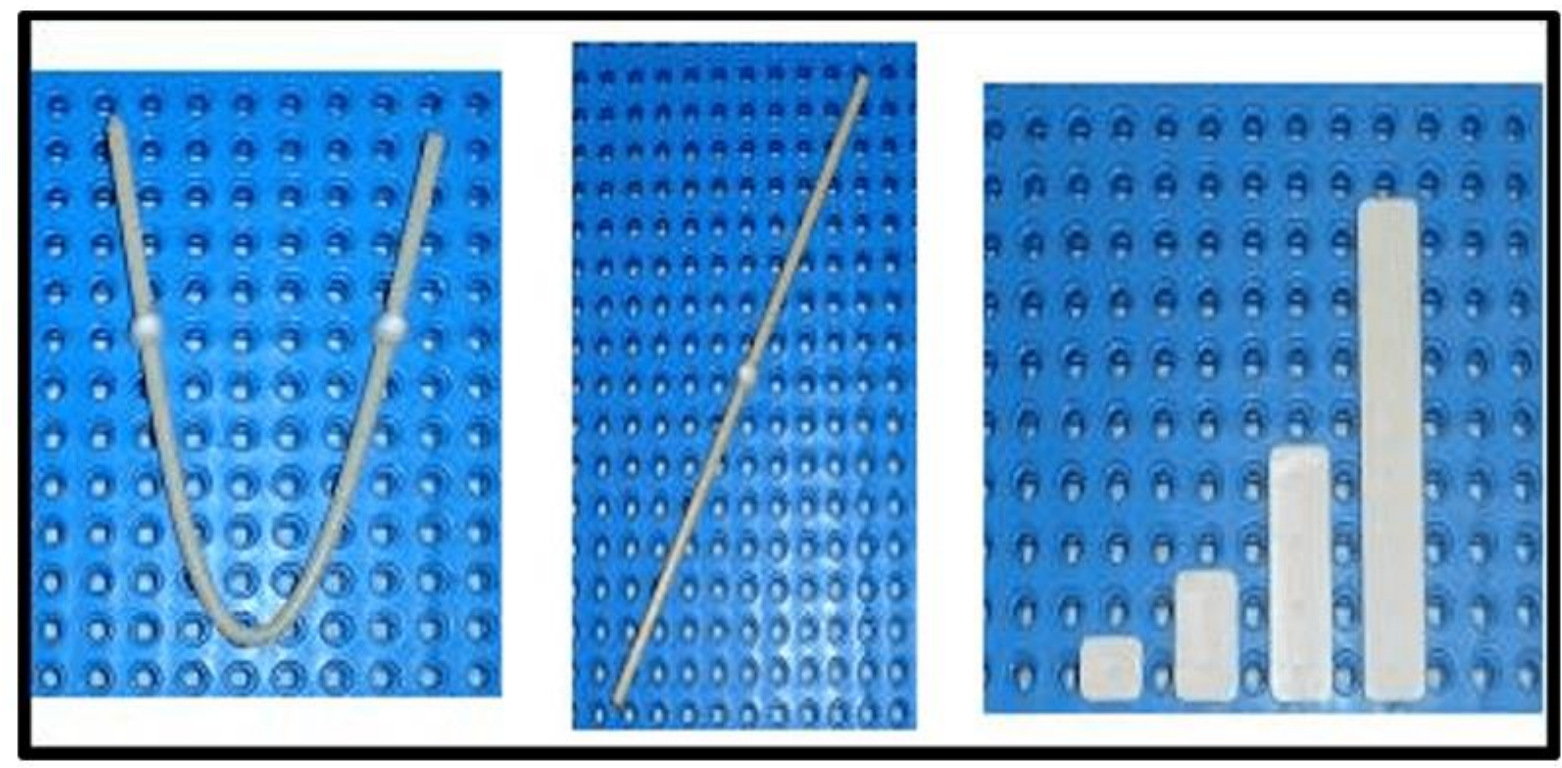

Fonte: $A$ autora (2021).

Esta ferramenta pedagógica proporciona ao discente uma aula lúdica, de modo que o educador, pode ensinar uma infinidade de conteúdos com o material, incluindo todos os alunos e não somente os deficientes visuais. Dentre os conteúdos que podem ser abordados estão: as quatro operações fundamentais da matemática, a tabuada, sendo está muito importante para a formação escolar, os divisores, os números primos, a raiz quadrada, produtos notáveis, triângulos, ângulos, funções, estatística, simetria, sendo estes conteúdos voltados para o ensino fundamental. No entanto também é possível trabalhar com o material no ensino superior, nos conteúdos de matrizes, trigonometria, integrais, entre outros (PINHEIRO, 2016).

Todos estes materiais podem ser utilizados nas salas de aula, e nas aulas de reforço, pois ajudam na compreensão dos estudantes, tornando os conteúdos interessantes. Até porque,

Os alunos não podem aguentar coisas obsoletas e inúteis, além de desinteressantes para muitos. Não se pode fazer todo aluno vibrar com a

RC: 94435

Disponível em: https://www.nucleodoconhecimento.com.br/educacao/mudancas-nametodologia 
beleza da demonstração do Teorema de Pitágoras e outros fatos matemáticos importantes. (D’AMBRÓSIO, 2009, p. 59).

No entanto, pode-se fazer o aluno interagir com uma aula lúdica, e vibrar com a mesma, tornando-a prazerosa. Desta forma quando o professor utiliza aulas dinâmicas, ele proporciona ao estudante meios que fazem com que o aluno se sinta encorajado, perdendo o medo de demostrar a aprendizagem. observa-se assim, que nas aulas de reforço muitas dificuldades são eliminadas devido ao fato, de que os alunos se sentem mais leves, e adquirem autoconfiança, sendo muito importante para a aprendizagem.

Acredita-se que ao utilizar o lúdico nas aulas e no reforço, percebe-se que, com algo diferente os alunos são capazes de se sentirem estimulados, e até mostram o gosto pela escola.

Desta maneira percebe-se que as aulas de reforço proporcionam aos estudantes grandes frutos, pois conforme os alunos vão aprendendo os conteúdos, eles vão recebendo resultados positivos, ou seja, notas melhores, demonstrando um avanço na aprendizagem. Sendo assim existem algumas vantagens ao proporcionar ao aluno as aulas de reforço: 1- Nas aulas de reforço os alunos contam com a atenção exclusiva do professor; 2 - O docente proporciona ao aluno uma aula exclusiva para o mesmo, atendendo a necessidade especifica do aluno, de modo que quando o aluno chega na sala de aula ele está com mesmo nível da turma, acontecendo assim a inclusão do aluno; 3- Com as aulas de reforço o aluno se sente apto para superar os desafios, que por ventura estava causando uma barreira na aprendizagem. Sendo assim é muito importante que a família apoie a criança, incentive, e proporcione a educação escolar regular e um reforço escolar na disciplina de matemática, pois a família influencia o desenvolvimento do aluno. É preciso entender que cada estudante tem seu tempo de aprendizagem, que nenhum indivíduo é idêntico a outro, mais que deve ter oportunidades iguais. 


\section{CONSIDERAÇÕES FINAIS}

Nessas considerações finais, observou-se que o professor deve transformar a aula tradicional, em uma aula prazerosa, onde todos os alunos participem dela ativamente, sendo assim, por meio de adaptações de materiais manipulativos, todos os estudantes podem adquirir o conhecimento, por métodos diferentes, promovendo assim a educação inclusiva dando condições para a participação dos alunos com necessidades especiais.

Observa-se que a forma de passar o conteúdo, precisa ser modificado pelos docentes, pois o método tradicional, o qual acontece de forma simples utilizando somente o quadro e o livro didático não dá a oportunidade a todos alunos de alcançar a aprendizagem, pois os alunos que precisam de um atendimento diferenciado ficam excluídos da turma, portanto é necessário que o docente reveja sua prática, e comece a criar possibilidades, como por exemplo, utilizando jogos, os quais podem ser adaptados para a deficiência do aluno, e também para o conteúdo abordado, de modo que todos os alunos sejam inseridos na sala de aula regular.

Observa-se durante a pesquisa que fica evidente que com a utilização dos materiais lúdicos adaptados para cada tipo de aluno, o ensino tradicional vai se modificando, e contribuindo para o desenvolvimento da aprendizagem, e para a inclusão dos alunos, pois na medida que é oferecido ao estudante maneiras diferentes de aprender o mesmo conteúdo, ele se sente curioso para observar como realizar a atividade com o aquele material. Pode-se utilizar como exemplo, o dominó, se o docente utilizar diferentes tipos de dominó nas aulas, os alunos ficaram encantados, com as possibilidades apresentadas para desenvolver a atividade, acontecendo assim a educação inclusiva, de modo que os alunos se sintam realmente incluídos na aula. Percebe-se que é muito importante desenvolver atividades diferenciadas para os alunos com deficiência, independentemente de suas condições físicas, intelectuais, sociais, emocionais. 
De modo que ao utilizar o lúdico, o educador consegue chamar a atenção dos alunos, as aulas ganham uma nova visão, o que antes era abstrato torna-se concreto e prazeroso para os discentes. Acredita-se que com a utilização de atividades diferenciadas, a escola e o professor contribuem para um olhar diferenciado e inclusivo dos estudantes.

Percebe-se que a inclusão somente obterá resultados satisfatórios, se houver compromisso de todos, ou seja, dos profissionais da educação e da família, para que o aluno se sinta realmente inserido na sala de aula, observa-se que é necessário que os alunos com deficiência e sem deficiência recebam o apoio da família, os quais devem incentivá-los, influenciando assim o desenvolvimento do discente. É preciso também que o governo invista em políticas públicas fornecendo formações para que o docente, aprenda como realizar cada tipo de atividade. Por meio desta parceria o estudante pode desenvolver-se melhor, e adquirir habilidades.

Observa-se também que seria interessante que os estudantes que sentem muita dificuldade participassem de aulas de reforço. Vale ressaltar que o reforço é importante para todos os estudantes, independente de possuírem alguma deficiência, pois nenhum aluno é igual ao outro, cada aluno tem um tempo para assimilar o conteúdo, e devem ser tratados de forma igualitária.

É importante frisar que o professor de reforço, dando ênfase na disciplina de matemática deve ser formado na área de atuação, outra coisa importante é a necessidade do professor que vai lecionar o reforço para alunos com deficiência, o qual também deve possuir formação específica na deficiência do aluno, tais como dominar os sinais de libras e a linguagem em braile. Já nas aulas regulares é necessário que o docente sempre utilize estratégias para incluir todos os alunos na aula, contribuindo assim para o desenvolvimento da aprendizagem, fortalecendo a educação inclusiva. 


\section{REFERÊNCIAS}

AZEVEDO, Orlando César Siade de. Operações Matemáticas com o Soroban (Ábaco japonês). Monografia (Graduação) - Universidade Católica de Brasília, Brasília, 2006. F.12.

BRASIL. Lei № 9.394, De 20 De Dezembro de 1996, Disponível em: http://www.planalto.gov.br/ccivil_03/leis/19394.htm, acesso em 24 de abril de 2021.

D'AMBRÓSIO, Ubiratan. Educação Matemática: da Teoria à Prática. 17ª̣edição.Campinas: Papirus, 2009.

DECLARAÇÃO DE SALAMANCA: Sobre princípios, políticas e práticas na área das necessidades educativas especiais. Salamanca: Espanha, 1994. Disponível em: http://portal.mec.gov.br/seesp/arquivos/pdf/salamanca.pdf, acesso em $10 \mathrm{de}$ Setembro de 2020.

DOS SANTOS, Simone Cardoso dos. A Importância do Lúdico no Processo Ensino Aprendizagem. Monografia apresentada ao curso de pós-graduação latosensu em Gestão Educacional, Universidade Federal de Santa Maria. RS, 2010. P.16

FACHIN, Zulmar.; FACHIN, Jéssica.; VINCE, Fernando Navarro. Educação Inclusiva e a Dignidade da Pessoa Humana. Londrina, PR: Thoth, 2018.

KUPFER, M. Cristina M. Duas notas sobre a inclusão escolar. In Escritos da criança, n.6 Centro Lydia Coriat, (pp. 71-82) Porto Alegre, RS.

MANTOAN, Maria Teresa Eglér. Inclusão escolar: o que é? por quê? como fazer?. $1^{1 \mathfrak{a}}$ edição. São Paulo: Moderna, 2006. 
PINHEIRO, Antonio Anderson; ARAÚJO, Aylla Gabriela Paiva de.; GONÇALVES, Lilia Santos. Multiplano como Auxílio no Ensino de Matemática para pessoas cegas. Anais II CINTEDI... Campina Grande: Realize Editora, 2016.

PONTES, Reinaldo Nobre.; CRUZ, Claudio. Roberto Rodriguez (org.). Educação inclusive e violência nas escolas. Belém:Unama, 2010.

SILVA SANTOS, Cristiane Cimelle da; COSTA, Lucinalva Ferreira da.; MARTINS, Edson. A Prática Educativa Lúdica: Uma Ferramenta Facilitadora Na aprendizagem $\mathrm{Na}$ Educação Infantil. ensaios pedagógicos revista eletrônica do curso de pedagogia das faculdades OPET, issn 2175-1773 - dezembro de 2015, disponível em: http://www.opet.com.br/faculdade/revista-pedagogia/pdf/n10/ARTIGO6.pdf, acesso em 18 de maio de 2020.

VIGOTSKI, Lev Semionovitch. Obras escogidas. Tomo V. Madrid: Visor, 1997.

WERNECK, Cláudia. Ninguém mais vai ser bonzinho na sociedade inclusiva. Rio de Janeiro: WVA, 1997.

Enviado: Julho, 2021.

Aprovado: Agosto, 2021. 